\title{
Socio Economic Survey on Waste Disposal Methods of Artisanal Maldive Fish Processing in Southern, Sri Lanka
}

\author{
Gammanpila A.M. ${ }^{*}$, Senadheera S.P.S.D and Dushani S.N. \\ Ocean University of Sri Lanka, Mattakkuliya, Sri Lanka \\ *shanigam@yahoo.com
}

\begin{abstract}
Maldive fish processing activities generate potentially large quantities of organic wastes and by-products from inedible fish parts, mainly from head and gastrointestinal sections. Therefore the present study was carried out in Kudawella, Kottegoda, Devundara and Mirissa in Sri Lanka with the primary purpose of investigating the waste disposal methods practiced by artisanal Maldive fish processors. Secondly, it investigated the potential of introducing better alternative methods for disposal of fish wastes in an eco-friendly manner. A questionnaire survey was conducted using a convenience sample of 32 artisanal Maldive fish processors. Data were analysed by employing SPSS 13.0 using descriptive statistics and some non-parametric statistic tools such as Friedman test and Wilcoxon singed rank test.
\end{abstract}

According to the findings, proportion of weight of raw material to weight of waste products was 5: 1. Over half of the Maldive fish processors (53.1\%) dispose their waste products directly to the sea as it was very convenient $(\mathrm{z}=-4.412, \mathrm{p}=0.05)$. Also they found that fish population become high in these waste discharging points in the sea as fishes attract to eat the discharging fish parts $(\mathrm{z}=-4.464, \mathrm{p}=0.05)$. Surprisingly, they do not see any harm to the environment $(\mathrm{z}=-4.049, \mathrm{p}=0.05)$ due to this direct discharge.

Almost all Maldive fish processors $(90.6 \%)$ agreed to follow another better practice for waste disposal if introduced. There was a statistically significant difference in most preferable methods for waste disposal such as 'Bio-gas production', 'Fish meal production', 'Composting' and 'Direct disposal' $(\chi 2=24.563, \mathrm{df}=3, \mathrm{p}=0.000)$. Majority of respondents (90.6\%) agreed to supply their fish waste products for fish meal or another by-product production. About $62.5 \%$ preferred to utilise bio-gas energy for Maldive fish processing activities.

Artisanal Maldive fish processors do not have sufficient knowledge and technology to practice these alternative methods for waste disposal. Therefore, fisheries extension programs should be conducted for Maldive fish processors to provide training on these environmental friendly practices. Further, processors should be educated about the economic importance of by-product value addition.

Keywords: Maldive fish, Waste disposal, Fish meal production, Bio-gas production 